\title{
Seroprevalence of COVID-19 antibody among patients visiting a large clinic in Uttar Pradesh
}

\section{Garima Agrawal ${ }^{1}$, Ruchira Agrawal ${ }^{2}$, Harsh Agrawal $^{3}$, Hiren Prajapati ${ }^{4 *}$, Krishna Yadav ${ }^{5}$, Kamal Agrawal ${ }^{6}$, Chandra Gupta Agrawal ${ }^{7}$}

\author{
${ }^{1}$ Associate Professor, B.J. Medical College, Ahmedabad, Gujarat, India \\ ${ }^{2}$ Consultant Monetary Research, National Health Authority Tower-1, New Delhi, India \\ ${ }^{3}$ Assistant Professor, Structural Interventional Cardiology, UCSF, California, USA \\ ${ }^{4}$ Assistant General Manager, Department of Medical Affairs, Eris Lifesciences Limited, Ahmedabad, Gujarat, India \\ ${ }^{5}$ Physician, Sitara Polyclinic, Lucknow, Uttar Pradesh, India \\ ${ }^{6}$ Chief Consultant Pathologist, Sitara Polyclinic, Lucknow, Uttar Pradesh, India \\ ${ }^{7}$ Chief Consulting Physician, Sitara Polyclinic, Lucknow, Uttar Pradesh, India
}

Received: 30 October 2021

Accepted: 24 November 2021

\section{*Correspondence:}

Dr. Hiren Prajapati,

Email: hiprajapati4042@gmail.com

Copyright: (C) the author(s), publisher and licensee Medip Academy. This is an open-access article distributed under the terms of the Creative Commons Attribution Non-Commercial License, which permits unrestricted non-commercial use, distribution, and reproduction in any medium, provided the original work is properly cited.

\begin{abstract}
Background: The study was conducted to determine the Coronavirus disease 2019 (COVID-19) antibody titre among patients who visited our clinic in Lucknow in order to find out the prevalence of sero positivity and to determine the association between COVID anti-body titre and positivity to different age groups, sex, and religions etc., if any.

Methods: Secondary data analysis was conducted at Lucknow's Sitara polyclinic from patients' data, who had attended the clinic between May 2021 and July 2021 and had universally undergone COVID antibody testing. COVID antibody (including IgG) levels in patients' blood were determined using Roche's commercial "Elecsys Anti-SARS-CoV2-cobas e411,601,602 system.by Roche which measure by Eclia (electro chemilusence immunoassay) quantitatively antibodies (including IgG). Patients with titres less than $1 \mathrm{u} / \mathrm{ml}$ were deemed seronegative for anti-SARS COVID-2, while those with titres greater than or equal to $1 \mathrm{u} / \mathrm{ml}$ were declared seropositive.

Results: The overall rate of seropositivity was $84.8 \%$. Around $84.5 \%$ males and $85.1 \%$ females were seropositive. Seropositivity was higher among 18 to 60 years of age. But there was no significant relation between mean age and seropositivity. Muslims had slightly higher seropositivity $(86.0 \%)$ as compared to non-Muslims (84.5\%). There was no significant difference between age and gender having positive COVID 19 antibody titres. Although the incidence of seropositivity was similar between Muslims and Non-Muslims, the antibody titres were significantly higher in Muslim patients.

Conclusions: In this part of central eastern UP, incidence of seropositivity could already be as high as $85 \%$, which is a pointer toward adequate herd immunity. COVID-19 does not differentiate on the basis of age, gender or religious affiliations. However, Muslims were found to have more antibody titres compared to non-Muslims, possibly related to life style, degree of exposure to COVID-19 virus and presence of inherent immunity.
\end{abstract}

Keywords: SARS-CoV-2, COVID-19, Seroprevalence

\section{INTRODUCTION}

Numerous epidemics and pandemics have claimed the lives of tens of millions of people worldwide. A new virus presents a threat to human life, economic security, and the healthcare system on a worldwide scale. Despite advances in health and science, we continue to confront this problem. The coronavirus causing the 2019-20 epidemic, 
known as SARS-CoV-2, was identified in Wuhan, Hubei Province, central China. ${ }^{1}$ Evidences suggest that a significant proportion of people infected with SARS CoV2 remain asymptomatic, but are still capable of infecting others. $^{2}$ On the other hand, the prevalence of asymptomatic SARS-CoV-2 infection has remained unknown, but it has been predicted to vary between $5 \%$ and $20 \%$ in published research. ${ }^{3,4}$ To manage COVID-19, it is critical to identify and isolate an infected individual early, to disrupt the transmission pathway. However, they do not need or seek medical care, which contributes to the disease's fast spread. As a result, health authorities cannot depend entirely on verified cases of COVID-19 identified by RT-PCR for containment efforts, as they may overlook asymptomatic and pre-symptomatic infections. ${ }^{5,6}$ To address this issue, the WHO and CDC have suggested conducting population-based sero-epidemiological surveys in order to produce data and apply appropriate containment measures. ${ }^{7,8}$ In India, the ICMR has also undertaken community-based sero-surveillance for severe acute respiratory syndrome-coronavirus-2 (SARS-CoV-2) in order to estimate and track infection rates in the general adult population. Serological testing and seroepidemiology substantially contribute to our understanding of disease transmission, population susceptibility, and the appropriate public health treatmalests. ${ }^{9}$ Uttar Pradesh is India's most populated state, with a population density of 828 inhabitants per square kilometre. COVID 19's second wave was 3.5 times quicker than the first wave in Lucknow. ${ }^{10}$ The purpose of this study was to determine seropositivity by estimating the titre of COVID-19 antibody among patients who visited Sitara Polyclinic in Lucknow and to determine the association between COVID anti-body positivity and titres to different age groups, sex, and religions.

\section{METHODS}

\section{Study setting, study period and study type}

It was a secondary data analysis conducted at Lucknow's Sitara Polyclinic. For the study, data from patients who attended the relevant clinic between May 2021 and July 2021 were used. Every patient was tested for COVID-19 antibody titre regardless of their clinical state throughout that time period unless the patient refused the same.

\section{Study participants, sample size and sampling technique}

Participants who had undergone the COVID antibody testing were sorted purposefully from the chosen database. Data from 998 eligible research participants were included into the analysis after cleaning and validation.

\section{Data collection}

Data collection began after ethical clearance. From the data base, information on the patients' demographic characteristics such as age, sex, and religion were gathered. COVID antibody titres of the selected patients were also collected.

\section{Measurement of COVID-19 antibody}

COVID antibody levels in patients' blood were determined using Roche's commercial "Elecsys Anti-SARS-CoV-2cobas system." It quantifies antibodies (including IgG) against SARS COV-2 using the ECLIA (Electrochemiluminescence Immunoassay) to the severe acute respiratory syndrome coronavirus (SARS COV-2) spike(s) protein receptor binding domain (RBD) in human plasma and serum. This test is used as an aid to assess humoral immune response to the SARS-COV -2 protein. It is reported to have $99.9 \%$ specificity and $98 \%$ sensitivity (For details please refer to broachers available with manufactures M/S ROCHE-cobas e 411,601,602).

\section{Interpretation of the COVID 19 antibody titre}

Patients with titres less than $1 \mathrm{u} / \mathrm{ml}$ were deemed seronegative for anti-SARS COV 2 while those with titres greater than or equal to $1 \mathrm{u} / \mathrm{ml}$ were declared seropositive.

\section{Data analysis}

Epi info CDC version 7 was used to input and analyse data. Percentages were used to represent categorical data, whereas the mean and standard deviation were used to represent continuous variables. The chi square test was used to determine the relationship between categorical variables, whereas the independent sample t test was used to determine the relationship between continuous variables. Statistical significance was defined as a $\mathrm{p}$ value less than 0.05 .

\section{RESULTS}

In present study as shown in Table 1, overall rate of seropositivity was $84.76 \%$. As shown in table 2 , overall mean age of the study participants was 50.24 years. Seropositivity among age group of 18 to 60 years was $85.66 \%$ while among 60 to 70 years and more than 70 years, it was $82.05 \%$ and $81.3 \%$ respectively (Table 1).

There was no significant age difference between seropositive and seronegative individuals ( $p$ 0.34). Age was also not significantly differed among lower and higher antibody titre levels (Table 3). Seropositivity among males and females were $84.5 \%$ and $85.1 \%$ respectively (Table 1 ).

As shown in Table 2 and Table 3, there was no significant gender wise difference among seropositivity for COVID19 antibodies nor for titre levels. As shown in Table 1,

Hindu participants were having seropositivity of $84.5 \%$ while Muslims were having $86 \%$. Seropositive status was not significantly differed across the religion in present study (Table 2, $\mathrm{p}=0.72$ ) but according to Table 4, prevalence of significantly higher titres $(>100)$ was more 
common among Muslims (33.5\%) as compared to Hindus $(23.21 \%)(\mathrm{p} 0.006)$ while lower titres between $10-50$ were more common (28.3\%) in Hindus compared to Muslim population $(18.9 \%)$.

Table 1: Seropositivity among study participants.

\begin{tabular}{|lll|}
\hline Seropositivity & Positive/out of $(\mathbf{N})$ & Percentages $(\%)$ \\
\hline Overall seropositivity & $846 / 998$ & 84.76 \\
\hline Gender & & \\
\hline Seropositivity in male & $492 / 582$ & 84.5 \\
\hline Seropositivity in female & $354 / 416$ & 85.1 \\
\hline Age groups & & 85.66 \\
\hline Seropositivity in age group 18-60 years & $657 / 767$ & 82.05 \\
\hline Seropositivity in age group 60-70 years & $128 / 156$ & 81.33 \\
\hline Seropositivity in age group >70 years & $61 / 75$ & \\
\hline Religion & & 84.5 \\
\hline Seropositivity in Hindus & $705 / 834$ & 86.0 \\
\hline Seropositivity in Muslims & $141 / 164$ & \\
\hline
\end{tabular}

Table 2: Relation of presence of COVID antibody with variables $(\mathbf{n}=998)$.

\begin{tabular}{|c|c|c|c|c|}
\hline & $\begin{array}{l}\text { COVID Antibody } \\
\text { present }(n=846)\end{array}$ & $\begin{array}{l}\text { COVID Antibody absent } \\
(\mathrm{n}=152)\end{array}$ & Total & P value \\
\hline Mean age (years) & $50.26 \pm 21.07$ & $50.09 \pm 15.72$ & $50.24 \pm 20.34$ & 0.92 \\
\hline \multicolumn{4}{|l|}{ Age groups } & \multirow{4}{*}{0.34} \\
\hline $18-60$ years & $658(85.7 \%)$ & $110(14.3 \%)$ & 768 & \\
\hline $60-70$ years & $128(82.1 \%)$ & $28(17.9 \%)$ & 156 & \\
\hline$>70$ years & $60(81.1 \%)$ & $14(18.9 \%)$ & 074 & \\
\hline \multicolumn{4}{|l|}{ Gender } & \multirow{3}{*}{0.85} \\
\hline Male & $492(84.5 \%)$ & $90(15.5 \%)$ & 582 & \\
\hline Female & $354(85.1 \%)$ & $62(14.9 \%)$ & 416 & \\
\hline \multicolumn{4}{|l|}{ Religion } & \multirow{3}{*}{0.72} \\
\hline Hindus & $705(84.5 \%)$ & $129(15.5 \%)$ & 846 & \\
\hline Muslims & $141(86.0 \%)$ & $23(14.0 \%)$ & 169 & \\
\hline
\end{tabular}

Table 3: Relation COVID antibody titres with variables $(\mathbf{n = 9 9 8 ) .}$

\begin{tabular}{|c|c|c|c|c|c|}
\hline & $\begin{array}{l}\text { Titre }<10 \\
(n=317)\end{array}$ & $\begin{array}{l}\text { Titre 10-50 } \\
(n=267)\end{array}$ & $\begin{array}{l}\text { Titre 50-100 } \\
(n=164)\end{array}$ & $\begin{array}{l}\text { Titre }>100 \\
(n=250)\end{array}$ & P value \\
\hline Mean age (year) & $49.01 \pm 15.61$ & $51.89 \pm 30.87$ & $50.37 \pm 14.97$ & $49.94 \pm 13.34$ & 0.4 \\
\hline \multicolumn{5}{|l|}{ Age groups } & \multirow{4}{*}{0.37} \\
\hline $18-60$ years & $248(32.3 \%)$ & $201(26.2 \%)$ & $126(16.4 \%)$ & $193(25.1 \%)$ & \\
\hline $60-70$ years & $41(26.3 \%)$ & $46(29.5 \%)$ & $24(15.4 \%)$ & $45(28.8 \%)$ & \\
\hline$>70$ years & $28(37.8 \%)$ & $20(27.0 \%)$ & $14(18.9 \%)$ & $12(16.2 \%)$ & \\
\hline \multicolumn{5}{|l|}{ Gender } & \multirow{3}{*}{0.36} \\
\hline Male & $197(33.8 \%)$ & $155(57.8 \%)$ & $92(15.8 \%)$ & $138(23.7 \%)$ & \\
\hline Female & $120(28.8 \%)$ & $112(26.9 \%)$ & $72(17.3 \%)$ & $112(26.9 \%)$ & \\
\hline
\end{tabular}

Table 4: Relation of religion and COVID-19 antibody titre $(n=998)$.

\begin{tabular}{|c|c|c|c|c|c|}
\hline Titre $\mathrm{u} / \mathrm{ml}$ & $\begin{array}{l}\text { Titre }<10 \\
(n=317)\end{array}$ & $\begin{array}{l}\text { Titre 10-50 } \\
(n=267)\end{array}$ & $\begin{array}{l}\text { Titre 50-100 } \\
(n=164)\end{array}$ & $\begin{array}{l}\text { Titre }>100 \\
(n=250)\end{array}$ & $P$ value \\
\hline Hindu & $26031.2 \%$ & $24528.3 \%$ & $14317.1 \%$ & $19523.4 \%$ & \multirow{2}{*}{0.006} \\
\hline Muslim & $5734.8 \%$ & $3118.9 \%$ & $2112.8 \%$ & $5533.5 \%$ & \\
\hline
\end{tabular}




\section{DISCUSSION}

The current study used clinic-based data analysis to ascertain seropositivity for COVID 19 in all patients attending to the Sitara Clinical, Lucknow, regardless of the nature, duration, or severity of their symptoms. Antibodies against COVID-19 are generated in the days to weeks after viral infection that a person was infected with the COVID19 virus, regardless of severity of illness or even asymptomatic infection. Antibody seropositivity surveillance in a community may be used to estimate the extent of infection and the cumulative incidence of infection in the population. ${ }^{11}$

The total seropositivity of COVID 19 was $84.76 \%$ in this Population. Seropositivity was detected in about $84.5 \%$ of males and $85.1 \%$ of females. Between July 2020 and December 2020, a study conducted in 12 cities in India by Velumany et al. ${ }^{12}$ discovered that $31 \%$ of seropositivity tests were positive for SARS-CoV-2 antibodies. Total sero-prevalence of SARS-CoV-2 in Nashik Municipal corporation, Aurangabad district and Maharashtra were $39.53 \%, 5.9 \%$ and $40 \%$ respectively. ${ }^{13-15}$ The present study was done during the phase of second wave of COVID 19. The high seropositivity means that these people are already been infected with SARS COV-2 either naturally or through vaccination although most of vaccinated patients were negative for this antibody. It may be due to reluctance in the following COVID appropriate behaviour. The difference in seroprevalence may be because of the difference in the study design, demographic profile of study population, and the situation of COVID-19 pandemic in each site.

In present study, all age groups showed more than $80 \%$ seropositivity. Mean age was not significantly related with COVID antibody titre either qualitatively or quantitatively. In a study done by Saple et al highest proportion (45\%) of anti-SARS-CoV-2 IgG antibody was in the age group 46-60 years followed by $44 \%$ in $36-45$ years. Although age was also not significant with seroconversion in that study. It's a fact of life that natural ageing is linked to immune system decline, as shown by increasing susceptibility to respiratory diseases like influenza and new coronaviruses. Some of these alterations contribute to the immune system's decline. Inflammaging, or age-related immune-mediated inflammation, and associated inflammatory illnesses, on the other hand, become more common as people become old. ${ }^{16}$

According to research by Jin et al, older age is linked to a greater number of comorbidities and, as a result, increased severity and death in COVID-19 patients. ${ }^{17}$ SARS-CoV-2 has resulted in a high rate of death among the elderly. In Europe, $90 \%$ of fatalities occurred in Italy, Spain, and France, and $95 \%$ happened in seniors over the age of 60 , the majority of whom had at least one underlying comorbidity. ${ }^{18}$
In present study, seropositivity among males and females were $84.5 \%$ and $85.1 \%$ respectively. In a study done by Saple et al, the proportion of seroconversion was $45 \%$ among females as compared to $35 \%$ in males. ${ }^{15}$ Although in either of the studies, the association was not statistically significant. Other studies like Dixit et al and Nagargoje et al also did not find any significant association with gender and COVID 19 antibody. ${ }^{13,14}$ It is interesting to note that most of adult females in our society remain confined to four walls of their house while males go out and work or help in procuring material for house hold requirements. Since COVID 19 positivity was equal, to be precise slightly higher in females. Why we can only surmise that virus come into the family equally through either male members or other means of spread defined by different authors, Males, however, are at a greater risk of adverse outcomes and mortality from COVID-19, regardless of their age. While COVID-19 is equally prevalent in males and females, male patients have a greater death rate. According to research conducted by Jin et al the number of males among dead patients is 2.4 times that of women. ${ }^{17}$ While males and women were equally susceptible, males were more likely to die. According to Bwire et al biological variations in males' and women's immune systems exist and may impair our capacity to fight infections such as SARS-2-CoV-2. ${ }^{19}$ Females are often more resistant to infection than males, which may be mediated by a variety of variables, including sex hormones and increased expression of coronavirus receptors (Angiotensin-converting enzyme 2) in males, but also by lifestyle factors such as greater rates of smoking and drinking among males. ${ }^{19}$

In the current study, significantly higher COVID 19 antibody titres were seen among Muslims. A similar study conducted recently in Malegaon also revealed that seropositivity was more among Muslims, and the association of religion with seropositivity was statistically highly significant. ${ }^{19}$ In a study conducted by Dixit et al in Aurangabad, Muslims had significantly higher (3.50 times) chance of developing sero-positivity, than others. ${ }^{14}$ A study conducted by Nagargoje et al in Nashik municipal corporation also showed significant relation with Muslim religion and seropositivity for COVD $19 .{ }^{13}$

High seropositivity is correlated with high virus circulation which means either public is violating lockdown and social distancing or may be due to taking of one or two doses of vaccinations. In either way, it means herd immunity has been established.

\section{CONCLUSION}

In this study central and eastern UP prevalence of seropositivity could already be as high as $85 \%$, which is a pointer towards adequate herd immunity. COVID 19 does not differentiate on the basis of age, gender or religious affiliations. However, Muslims were found to have more antibody titres compared to non-Muslims, possibly related to lifestyle, degree of exposure and presence of inherent 
immunity. Although high seroprevalence may give some kind of false sense of security but till date little is known about the protective titres of the antibodies and the duration for which they stay in blood. It is necessary to strictly follow COVID appropriate behaviour.

\section{ACKNOWLEDGEMENTS}

We acknowledged the contribution made Mr. Kamal Agrawal in-charge Sitara Polyclinic for giving us access to all COVID 19 antibody and other test reports. We also acknowledged Mr. Ashutosh Goel of Eris Life Sciences Ltd for providing through his organisation financial support as well as facilitating the publication of this article.

\section{Funding: No funding sources}

Conflict of interest: None declared

Ethical approval: The study was approved by the Institutional Ethics Committee

\section{REFERENCES}

1. Chams N, Chams S, Badran R, Shams A, Araji A, Raad M et al. COVID-19: a multidisciplinary review. Frontiers in public health. 2020;8:383.

2. Oran DP, Topol EJ. Prevalence of asymptomatic SARS-CoV-2 infection: a narrative review. Annals of internal medicine. 2020173(5):362-7.

3. Bai Y, Yao L, Wei T. Presumed asymptomatic carrier transmission of COVID-19. JAMA;2020.

4. Zou L, Ruan F, Huang M. SARS-CoV-2 viral load in upper respiratory specimaless of infected patients [Letter]. N Engl J Med. 2020;382:1177-9.

5. Moghadas SM, Fitzpatrick MC, Sah P, Pandey A, Shoukat A, Singer BH et al. The implications of silent transmission for the control of COVID-19 outbreaks. Proceedings of the National Academy of Sciences. 2020;117(30):17513-5.

6. Wu J, Liu X, Zhou D, Qiu G, Dai M, Yang Q et al. Identification of RT-PCR-negative asymptomatic COVID-19 patients via serological testing. Frontiers in public health. 2020;8:267.

7. CDC. COVID-19 Serology Surveillance Strategy. Cited through Available at: https://www.cdc.gov/coronavirus/2019-

ncov/COVID-data/serology-surveillance/index.html. Accessed on 12th October 2021.

8. World Health Organization. Coordinated global research roadmap: 2019 novel coronavirus; March 2020. Geneva: WHO; 2020. Available at: https://www.who.int/blueprint/priority-diseases/keyaction/Coronavirus_Roadmap_V9.pdf. Accessed on 12th October 2021.

9. Kumar MS, Bhatnagar T, Manickam P, Kumar VS, Rade K, Shah N et al. National sero-surveillance to monitor the trend of SARS-CoV-2 infection transmission in India: Protocol for community-based surveillance. The Indian Journal of Medical Research. 2020;151(5):419.

10. TNN / Apr 4, 2021. (n.d.). Lucknow: Second wave of COVID-19 pandemic 3.5 times faster than 2020 surge: Lucknow News - Times of India. The Times of India. Available at: https://timesofindia.indiatimes.com/city/lucknow/luc know-second-wave-of-COVID-19-pandemic-3-5times-faster-than-2020-

surge/articleshow/81893359.cms. Accessed on 12 October 2021.

11. Huang AT, Garcia-Carreras B, Hitchings MD, Yang B, Katzelnick LC, Rattigan SM et al. A systematic review of antibody mediated immunity to coronaviruses: kinetics, correlates of protection, and association with severity. Nature communications. 2020;11(1):1-6.

12. Velumani A, Nikam C, Suraweera W, Fu SH, Gelband $\mathrm{H}$, Brown PE et al. SARS-CoV-2 Seroprevalence in 12 Cities of India from July-December 2020. medRxiv. 2020.

13. Nagargoje B, Palod A, Dixit J, Yelikar K, Andurkar S, Badgujar S. Seroprevalence of COVID-19 in a City in India: A Community-based Cross-Sectional Study. J Res Med Dent Sci. 2021;9(9):48-53.

14. Dixit JV, Iravane J, Andurkar SP. Seroprevalence of COVID-19 in Aurangabad district. IJCRT. 2020;8 (9):3675-83.

15. Saple P, Gosavi S, Pawar T, Chaudhari G, Mahale H, Deshmukh P, et al. Seroprevalence of anti-SARSCoV-2 of IgG antibody by ELISA: Community-based, cross-sectional study from urban area of Malegaon, Maharashtra. J Family Med Prim Care. 2021;10:14538.

16. Bajaj V, Gadi N, Spihlman AP, Wu SC, Choi CH, Moulton VR. Aging, immunity, and COVID-19: how age influences the host immune response to coronavirus infections?. Frontiers in Physiology. 2021;11:1793.

17. Jin JM, Bai P, He W, Wu F, Liu XF, Han DM et al. Gender differences in patients with COVID-19: focus on severity and mortality. Frontiers in public health. 2020;8:152.

18. Bhatia R, Abraham P. The enigmatic COVID-19 pandemic. The Indian Journal of Medical Research. 2020;152(1-2): 1 .

19. Bwire GM. Coronavirus: why males are more vulnerable to COVID-19 than women? SN comprehensive clinical medicine. 2020;2(7):874-6.

Cite this article as: Agrawal G, Agrawal R, Agrawal H, Prajapati H, Yadav K, Agrawal K et al. Seroprevalence of COVID-19 antibody among patients visiting a large clinic in Uttar Pradesh. Int $\mathbf{J}$ Basic Clin Pharmacol 2022;11:8-12. 